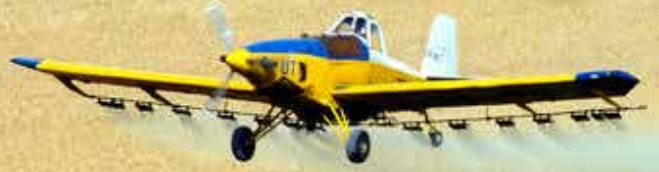

\title{
Monetisation of sustainability impacts of food production and consumption
}

Tommie Ponsioen, Gohar Nuhoff-Isakhanyan, Theun Vellinga, Willy Baltussen, Koen Boone, Geert Woltjer 



\section{Monetisation of sustainability impacts of food production and consumption}

Tommie Ponsioen, Gohar Nuhoff-Isakhanyan, Theun Vellinga, Willy Baltussen, Koen Boone, Geert Woltjer

This study was carried out by Wageningen Economic Research and was commissioned and financed by the Dutch Ministry of Agriculture, Nature and Food Quality within the context of the 'Resource Use Efficiency' research theme of the Knowledge Base (project number KB-30-004-009)

Wageningen Economic Research

Wageningen, June 2020

REPORT

2020-010

ISBN 978-94-6395-418-1 
Tommie Ponsioen, Gohar Nuhoff-Isakhanyan, Theun Vellinga, Willy Baltussen, Koen Boone, Geert Woltjer, 2020. Monetisation of sustainability impacts of food production and consumption. Wageningen, Wageningen Economic Research, Report 2020-010. 24 pp.; 4 fig.; 4 tab.; 17 ref.

Binnen WUR lopen diverse projecten die een framework bieden om duurzaamheid van voedsel in agrarische ketens te meten. Voor de beslissingsondersteuning van bedrijven, overheid en consumenten is het belangrijk dat de verschillende duurzaamheidskenmerken in één eenheid uitgedrukt kunnen worden. Monetarisatie is één mogelijke weg. De (on)mogelijkheden worden binnen dit KB-traject op een rij gezet. Er wordt geadviseerd om de door de Europese Commissie goedgekeurde LCA-benadering als startpunt van de analyses te gebruiken.

WUR developed several frameworks to measure the sustainability of food in agricultural chains. To support decision making of firms, farms, government and consumers it is important to be able to compare the different sustainability issues. Monetisation is one way to express all issues in one unit. The possibilities for monetisation will be investigated in this knowledge base project. It is suggested to use the LCA methodology approved by the European Commission as a starting point for such a valuation approach.

Key words: Sustainability, Life Cycle Analysis, monetisation, food

This report can be downloaded for free at https://doi.org/10.18174/522812 or at www.wur.eu/economic-research (under Wageningen Economic Research publications).

(C) 2020 Wageningen Economic Research

P.O. Box 29703, 2502 LS The Hague, The Netherlands, T +31 (0)70 3358330 ,

E communications.ssg@wur.nl, http://www.wur.eu/economic-research. Wageningen Economic Research is part of Wageningen University \& Research.

\section{(cc) BY-NC}

This work is licensed under a Creative Commons Attribution-Non Commercial 4.0 International License.

(c) Wageningen Economic Research, part of Stichting Wageningen Research, 2020

The user may reproduce, distribute and share this work and make derivative works from it. Material by third parties which is used in the work and which are subject to intellectual property rights may not be used without prior permission from the relevant third party. The user must attribute the work by stating the name indicated by the author or licensor but may not do this in such a way as to create the impression that the author/licensor endorses the use of the work or the work of the user. The user may not use the work for commercial purposes.

Wageningen Economic Research accepts no liability for any damage resulting from the use of the results of this study or the application of the advice contained in it.

Wageningen Economic Research is ISO 9001:2015 certified.

Wageningen Economic Research Report 2020-010 | Project code 2282100281

Cover photo: Shutterstock 


\section{Contents}

$\begin{array}{ll}\text { Abbreviations/Definitions } & 5\end{array}$

1

$\begin{array}{lr}\text { Introduction } & 6\end{array}$

$\begin{array}{lll}1.1 & \text { Research question } & 7\end{array}$

$\begin{array}{lll}1.2 & \text { Approach } & 7\end{array}$

$\begin{array}{lll}1.3 & \text { Conceptual framework } & 8\end{array}$

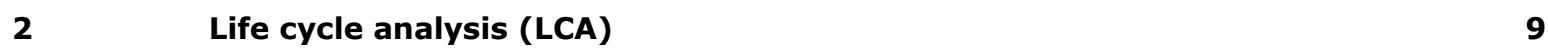

2.1 The LCA approach 9

$\begin{array}{ll}2.2 & \text { Environmental categories } \\ 2.3 & 10\end{array}$

$\begin{array}{lll}2.3 & \text { Aggregation issues } & 11\end{array}$

$3 \quad$ Methods to monetise environmental damage $\quad 12$

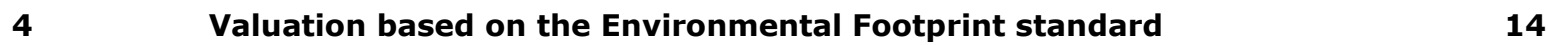

$5 \quad$ Valuation based on the ReCiPe 2016 method $\quad 18$

$\begin{array}{llr}6 & \text { Other approaches } & 19\end{array}$

6.1 CE Delft shadow price calculation (De Bruyn et al., 2017) 19

6.2 Stepwise (Weidema) 19

$\begin{array}{llr}7 & \text { Uncertainty analysis } & 21\end{array}$

8 Conclusion $\quad 22$

$\begin{array}{ll}\text { References and websites } & 23\end{array}$ 



\section{Abbreviations/Definitions}

LCA
LCIA
DALY
Species.year
QUALY
YOLL
VSL
VOLY
Endpoint indicator
Midpoint indicator
WTA
WTP

Environmental price

\author{
Life Cycle Analysis \\ Life Cycle Impact Analysis \\ Disability Adjusted Life Year \\ Extinct species per year \\ Quality-Adjusted Life Year \\ Year Of Life Lost \\ Value of a Statistical Life \\ Value Of a Life Year
}

Aggregated indicator, i.e. health, biodiversity and resource scarcity

Indicator that focuses on a single environmental issue

Willingness To Accept

Willingness To Pay

Societal cost of pollution or other environmental disturbances in euros per kilogram of pollutant or a similar unit 


\section{Introduction}

This is an internal discussion/working document of Wageningen Research on monetisation of impacts related to sustainability of food production and consumption. Monetisation is the practice of quantifying the external impacts and converting these measures of impacts into monetary units (Pizzol et al., 2015). The initial scope is limited to environmental impacts, but the ambition is to cover all relevant sustainability topics in the long run.

The production and consumption of food and drinks have important impacts on the environment by increasing depletion of natural resources, converting natural ecosystems into agricultural and urban areas, and polluting air, soil and water. Next to the environmental impacts, food and drinks production and consumption may also have impacts on social, human and economic capital. It is a challenge to take all these issues and their interactions into account. Sustainable development in the value chains of food is one of the top priorities of Wageningen University \& Research, but related projects often focus on specific issues (climate change, animal welfare, healthy food, etc.), while not considering the bigger picture and may therefore neglect other relevant topics or ignore possible trade-offs. Some projects do cover multidisciplinary topics, but struggle with comparing environmental and socioeconomic issues.

Even environmental researchers struggle to find an objective way to assess the relative importance of sustainability issues. An approach to objectivise the relative importance of sustainability issues is the monetisation. Monetisation is built on the following principles: (1) sustainability issues are quantified in indicators and (2) indicators are converted into monetary values representing the external cost of each issue and (3) monetary values are aggregated to determine the total impact and the contribution of each issue. Despite its increasing popularity, this approach is criticised as being subjective and unreliable, where results depend to a large extent on experts' estimates of the quantitative effects and monetary values of these effects. On the one hand, there is hardly a better - if no - alternative for setting priorities for all sustainability issues. On the other hand, many researchers and experts may disagree with the choices that we have to make for monetisation. Monetisation therefore requires transparency on the assumptions and variability, by making limitations explicit and by being cautious in conclusions and giving room for debate on the findings.

If we can find a way to do this, we can help clients to respond to their demands: policy makers can address the knowledge from monetised assessments by implementing policy instruments (e.g. to stimulate the consumption of plant-based protein sources by higher taxes on meat and lower taxes on plant-based alternatives), and companies can use the knowledge to prioritise investments. NGOs may identify priorities and convince and help policy makers and companies to take action. Consumers may use this information (if put on labels) to make better consumption decisions (e.g. by discriminating against products which have a high social external cost). Monetisation not only shows the relative importance of different sustainability issues for food products and prioritisation where trade-offs occur, but may also provide relevant information on the advantages to invest in mitigation of impacts in terms of monetary value.

The three main goals for applying monetisation are:

1. to be better able to assess the relative importance of each sustainability issue, also referred to as impact category (climate change, land use, fossil resource depletion, animal welfare, child labour, social status, consumer health, etc.)

2. to better asses the consequences of switching from one way of producing and consuming to another on the total impact and the relative importance of the consequences in each impact category to be able to prioritise in cases of trade-offs

3. to provide an indication of the absolute impact of a product in terms of external costs and benefits expressed in monetary units per unit of product and by that support comparative product evaluation. 


\subsection{Research question}

- When considering the monetisation approach, which methods are available to assess the environmental external costs of food production and consumption and how do we judge their scientific robustness and relevance for each of the three purposes?

- What is the best starting point for developing a monetisation approach that is broadly accepted and scientifically sufficient robust?

- As a side condition it is requested that the method that is developed be applicable to various sectors of agri-food (livestock, horticulture).

\subsection{Approach}

There are several approaches available that calculate monetary values of externalities. Roughly two approaches may be distinguished: the welfare based and the rights based approach. An important requirement of each methodology is that it is transparent, easy to explain also to both experts and non-experts, and that it is broadly accepted.

For environmental evaluation a long history is already available through Life cycle analysis (LCA), with general procedures accepted by the EU, and more or less broadly accepted procedures for aggregation. If all LCA indicators are integrated into one indicator according to these LCA methodologies, then only one price has to be determined for this indicator in order to get a monetary value of all indicators. The EU methodology is seen as the state-of-the-art methodology internationally and provides such an indicator that is determined after long discussions. Furthermore, there is standard and seemingly flexible software available for the calculation of the environmental effects. For this reason we see the LCA methodology as a good starting point for the development of a methodology to calculate monetary values for environmental externalities.

LCA consists of 4 basic steps: goal \& scope definition, life cycle inventory, impact assessment and interpretation. The life cycle inventory is a model in which all processes that can be directly or indirectly related to the production and consumption of the studied product are listed. All phases in the life cycle of a product are considered (see Figure 1). For each process the inputs and outputs, including all environmental interventions, are quantified. An environmental 'intervention' is a term used in LCA that means a list of all effects on the environment. The list of all environmental effects is called an intervention profile. The next step is to convert the intervention profile into a number of indicators and aggregate them. Subsequently, the indicators can be converted into monetary units (see Figure 2).

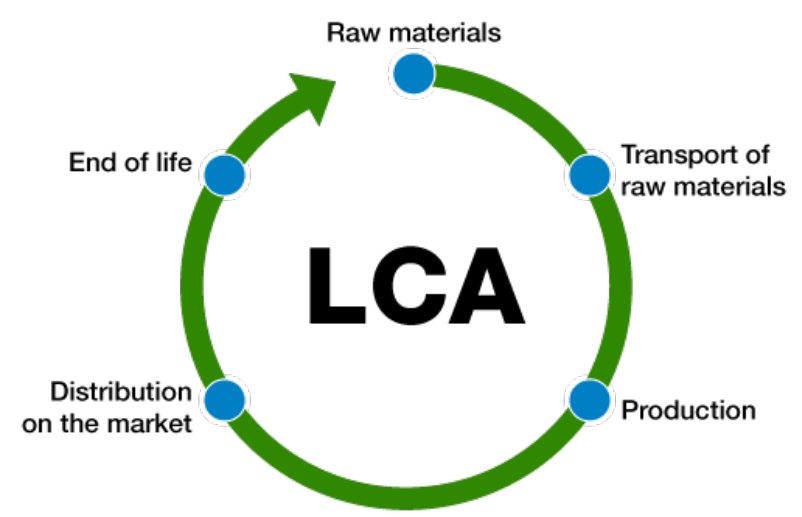

Figure 1 LCA contains all phases in the life cycle of a product 
Figure 2 Steps from a description of all processes to an estimate of external costs

\subsection{Conceptual framework}

Figure 3 presents the conceptual framework of this report which reflects the basic steps of the LCA approach discussed above, with as a main modification that a monetisation step is now added to this (see right 'column' of Figure 3).

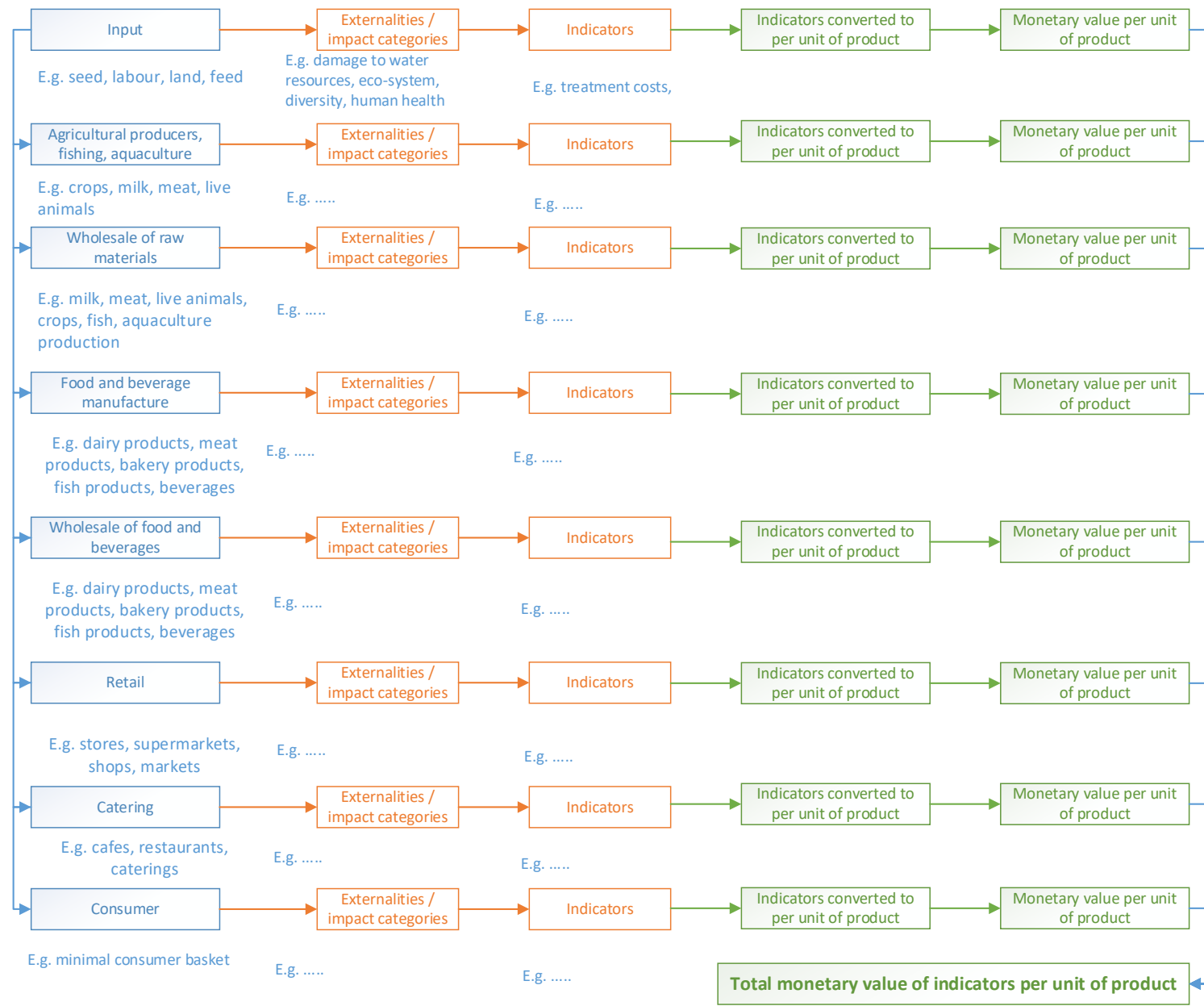

Figure 3 Conceptual framework 


\section{Life cycle analysis (LCA)}

\subsection{The LCA approach}

Life cycle analysis (LCA) is a widely used technique to assess the environmental impacts of products. It quantifies the environmental impacts of each component of the product, and systematically analyses the environmental impacts of each phase from raw material, transport, and production. It may also include the environmental impacts of use and disposal of the product at the end of its life. The method is internationally recognised and standardised.

LCA gives an environmental footprint of different products, but may also be applied to evaluation of for example changes in legislation or specific policies. An LCA provides indicators that give an integral picture of environmental effects of a product through the whole value chain, may help to identify hotspots where negative environmental impacts may be reduced, shows potential trade-offs between solving environmental impacts at different phases of the value chain and allows to compare the environmental impacts of similar products.

In an LCA study, the product system is defined by a number of processes that are contributing to the production (and consumption) of the product, including the supply chains of inputs and the processing of waste. For each process the inputs and outputs, and the environmental interventions (meaning emissions to the environment, resource extractions from nature, and land use) are quantified. All interventions that can be attributed to the product are then aggregated per unit of product, and converted into impact indicators.

Besides the uncertainties of the foreground data (i.e. the explicit data about the production process that are directly collected) and especially the background data (standardised values for different processes) and methodological choices on which processes to include or exclude, the methods for converting the environmental interventions to indicators also introduces uncertainties and subjective choices.

In LCA a difference is made between midpoint and endpoint indicators. Midpoint indicators aggregate the emissions to a level where little value judgements are needed. For example, the different greenhouse gasses are aggregated to carbon equivalents. The categories to which the emissions and other interventions are aggregated are called impact categories, where this aggregation process is called characterisation in LCA analysis. Endpoint indicators are indicators that are directly related to the final effects on an area of protection (also called safeguard subject). Examples of areas of protection are human health, ecosystems quality, and resource depletion/scarcity. Less common in LCA are the evaluation of impacts on ecosystems services, animal welfare, or economic productivity. Endpoint indicators can be seen as weighted averages of midpoint indicators, and have as an advantage that they are directly related with human wellbeing, but have as a disadvantage that in aggregation the uncertainty is very high and that in many cases many assumptions are needed to get the result.

Ideally, we would like to have one indicator summarising the environmental impact, where all interventions can be aggregated to a single score. One way to do this is by normalisation and weighting. Normalisation is dividing impact indicator results of a product by their values in a reference situation, such as the total impact per capita in Europe due to interventions that took place during one year. In this way, the unit of each indicator becomes a person-year equivalent. Weighting can then be done by for example panel weighting: a number of experts and/or laymen is asked to give weights to each category. The average weights are then applied to the normalised results. Normalisation and weighting can be either done at midpoint or endpoint level. The problem with midpoint weighting is that there are too many topics for the panel to grasp at once. A solution could be to do normalisation and weighting at the endpoint stage, but this involves highly uncertain indicators. A new approach is 
to ask the panel to first give weights to the endpoint categories and then to the midpoint categories within each endpoint category at a time (there are about 7 midpoint indicators that can be converted to each endpoint indicator). The advantage of having one indicator is that all consequences of production and consumption of a product can be valued, the disadvantage is the implicit or explicit value judgements that are needed to reach this high level of aggregation.

Another approach is to monetise the midpoint or endpoint impact indicators, where the environmental impact is viewed as damage to natural capital. Monetisation can thus be a way to make these issues more comparable. Several methods exist to convert environmental impacts into monetary units. One is to directly monetise the interventions, which can be very precise, but there are many different types of interventions, which make this data demanding. Another way is to monetise the most common interventions per impact category and rely on the midpoint indicators. This is the approach that is for example used by CE-Delft (De Bruyn et al., 2017). For some impact categories this may be difficult due to lack of data, for example in case of toxic substances and smog forming emissions, in which case the endpoint indicator for human health can be monetised instead. The logic is that everything that is included in the monetisation of midpoint indicators is excluded from the endpoint indicators.

\subsection{Environmental categories}

The following midpoint impact categories are often associated with the production and consumption of food and beverage products, with the endpoint indicators listed below them:

- Greenhouse gas emissions (mainly carbon dioxide, methane and nitrous oxide emissions to air) and capture/storage of carbon dioxide, affecting climate change, which results in

- human health damage (flooding and diseases),

- biodiversity loss (flooding and diseases), and

- human welfare loss (for example, property damage, public infrastructure damage, changes in cost for cooling and heating indoor spaces, revenue losses in the tourist industry, agricultural production losses or productivity changes).

- Air polluting emissions, such as fine particulates $(<2.5 \mathrm{um})$, sulphur dioxide $\left(\mathrm{SO}_{2}\right)$, nitrogen oxides (NOx), ammonia $\left(\mathrm{NH}_{3}\right)$, and non-methane volatile organic compounds (NMVOCs), causing

- particulate matter formation, photochemical ozone formation, which mainly affect human health (respiratory diseases), and

- acidification, which mainly affects biodiversity loss (some species are more adapted to acidity than others).

- Toxic emissions (to air, soil and water), such as metals and agrochemicals, causing

- human diseases (cancer and non-cancer diseases, such as damage to organs, the brain, or immune system and development disorder) and

- biodiversity loss (due to lethal exposure to the toxic substances).

- Eutrophying emissions, such nitrate and phosphate leaching to water, which affects mainly

- biodiversity (some species profit more from the abundance of the macronutrients than others) and

- human welfare (reduced value of waterside property, increased cost of water treatment, reduced value of the waterways for commercial and recreational uses, revenue losses in the tourist industry).

- Land transformation from natural ecosystems to agricultural and industrial land and subsequent land occupation for agricultural and industrial purposes, affecting

- biodiversity (permanent or temporal habitat loss), and

- ecosystem services (provisioning services, such as food, water, and genetic, medicinal and ornamental resources; regulating services, such as regulation of air quality, climate, water quality and flows, soil quality, nutrient cycling, pollination and biological control; and cultural services, such as recreation and cognitive development).

- Freshwater consumption (net extraction of freshwater from a watershed system), affecting

- human health (poor availability of clean drinking water),

- biodiversity (some species can adapt better to drought than others), and

- human welfare (clean freshwater becomes more expensive to extract or produce). 
- Fossil resource extraction, which affects

- human welfare (fossil resources become more expensive to extract, regional dependencies may influence international power relations, resource price uncertainty, fraud, international conflicts and migration).

- Mineral resource extraction, which affects

- human welfare (mineral resources become more expensive to extract).

\subsection{Aggregation issues}

In most cases the results of an LCA for different systems and different regions are aggregated. For example for greenhouse gas emissions this is relatively easy because these have a global effect. However, for most other categories this has fundamental problems. For example, when aggregating particulate matter formation the effect is local and depends for example on population density and the current level of particulate matter concentration. In standard LCA only a distinction is made between high and low population density and nothing in between is considered. It is, however, also possible to use continuous functional forms. Some effort has been made to develop and implement countryspecific characterisation factors for water consumption, eutrophying and acidifying emissions and land use. This increases already precision, but certainly for large countries this may still not be accurate enough. Where more specific data are available, this can be used, but this involves time-consuming work as the current software is not capable to process such information automatically.

Most interventions (i.e. changes in emissions of natural capital stock as a consequence of processes in consumption and production) defined in standard LCA don't differentiate between different kinds of processes. This implies that technologies that are more efficient from an environmental perspective are not always visible in the results of the analysis. Only land transformation and land occupation interventions are specified per type of land use (e.g. annual, perennial crops, forestry, grassland, etc., specified whether irrigated/non-irrigated/unspecified, intensive/extensive/unspecified, tropical/deciduous forest, etc.). However, most impact assessment methods do not calculate impacts more specific than aggregated land use change due to insufficient reliable data. For example, coffee plantations and apple plantations are both classified as perennial crops, but may have completely different effects for biodiversity (even if they were cultivated in the same country), which is not accounted for in a standard LCA. Such data are very scarce and therefore the default factors or estimates are used instead.

With respect to geographical differences, only greenhouse gas emissions have the same impact irrespective of where they are emitted. For fossil and mineral resource extraction, it is generally accepted to ignore different effects depending on the location where they are extracted because they are traded on a global market. All other interventions have different impacts depending on the local circumstances. Due to technical limitations of software, geographically specific characterisation factors have not yet been implemented for all impact categories. Additional research questions are therefore:

- To what extent can we take specific land use types and geographically specific life cycle impact analysis into account?

- To what extent do the existing monetisation methods take specific land use types and spatially specific interventions into account?

- To what extent can we take specific land use types and spatially specific interventions into account in the development of an alternative monetisation method? 


\section{Methods to monetise environmental damage}

When priorities are set on reducing different environmental impacts implicit or explicit weights are used and in this study the focus is on those that are implicitly or explicitly formulated as monetary values. The challenge is to monetise these implicit weights based on a consistent and robust method. The standard available methods can be summarised as:

- Abatement/Avoidance cost

- Revealed preference:

- Travel cost (recreational sites)

- Hedonic pricing (e.g. house prices)

- Stated preference

- Contingent valuation (asking normally for the willingness to pay, WTP)

- Choice experiments (based on choices made in experiments based on WTP).

Let us summarise these main approaches to monetisation. First, a choice must be made between an abatement cost and a preference (abatement benefit) approach (Figure 4). Marginal abatement cost is the cost of reducing the environmental pollution by one unit. This may be a method to restore the damage, for example by cleaning polluted water, but may also be the implementation of a less polluting production method in another industry (opportunity cost). The preference approach tries to find out what the disutility and costs are that are generated by a marginal increase in pollution, which starts with the fictive assumption that a market for the externality would exist. In equilibrium in such a hypothetical market, the marginal abatement costs are equal to the marginal costs from a preference point of view. If preferences are sorted according to a demand curve, and the costs are sorted according to a supply curve, then the effect is formally the same in equilibrium $E$, but fundamentally different if no equilibrium is reached (see Figure 4).

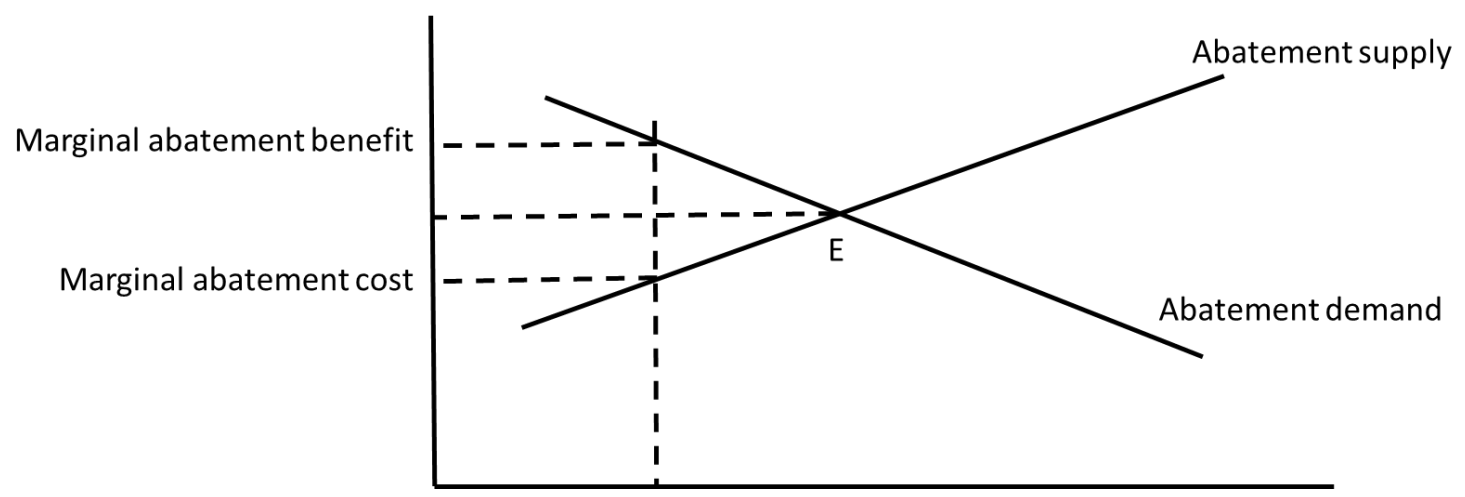

Figure 4 Abatement market

If we look at the preference approach, the analysis may be based on modelling a utility function, i.e. a very abstract approach, by empirical investigation of choices made by people, or by asking people in an intelligent manner about their choices or their values. If we look at the abatement cost side, then available production technologies in combination with prices of inputs used are the theoretical background.

Let us investigate a little bit more in depth the methods used to investigate preferences related with pollution. 


\section{Revealed preference and willingness to pay for environmental quality or willingness to}

accept the damage. Revealed preference assumes that the best way to measure consumer preferences is to observe purchasing behaviour. Revealed preference theory assumes that consumers have considered a set of alternatives before making a purchasing decision. Revealed preference studies are methods where researchers observe individuals' actual behaviour and use this behaviour to make inferences about the willingness to pay.

a. Hedonic pricing measures preferences by modelling the price of a specific commodity, like houses, depending on a number of variables, including the attributes that are to be monetised. The implicit monetary value is determined by the parameters of this price equation.

b. Travel cost analysis, or Clawson's method, uses the time and expenditures for travel towards a specific site as an indication for the preference to visit this site. The costs made, including a monetary valuation of time, are an indication of the preferences in monetary units.

Note that an essential characteristic of revealed preference methods is that there is a reliable and relevant parallel market that can be used for determining the financial inferences. It is obvious that such a market does not exist for all externalities.

2. Stated preference method or Contingent valuation is a method of estimating the value that a person places on a good by asking people to directly report their willingness to pay (WTP) to obtain a specified good, or willingness to accept (WTA) to give up a good, rather than inferring them from observed behaviour in regular market places. One way to value potential environmental damage is by assessing stated preferences by asking peoples willingness to pay for environmental quality or willingness to accept the damage. These methods directly ask what you would like to know, but are not very reliable because people have difficulties to imagine how they would behave.

Stated preference methods rely on answers on carefully worded survey questions (see for example Johnston et al., 2017). Those answers - in the form of monetary amounts, choices, ratings, or other indications of preference - are scaled following an appropriate model of preference to yield a measure of value. Stated preference studies use survey techniques to query individuals about their preferences. Such a valuation may also be accomplished through choice experiments. The advantage of choice experiments is that it feels more realistic for the participants.

A fundamental issue is to what extent the focus is on the willingness to pay or the willingness to accept. The figures resulting from the willingness to pay are normally much lower than figures from the willingness to accept. Explanations for this are differences in the budget constraint and psychological mechanisms.

a. Willingness to pay (WTP) is the maximum price at or below which a consumer will definitely buy one unit of a product. This corresponds to the standard economic view of consumer reservation price.

b. Willingness to accept (WTA) is the minimum amount of money that a person is willing to accept to abandon a good or to put up with something negative, such as pollution. It is equivalent to the minimum monetary amount required for sale of a good or acquisition of something undesirable to be accepted by an individual.

A specific issue to be investigated is to what extent valuation results from one source can be transferred to other studies (see for example Ready et al., 2004). By doing this, a lot of money and effort is saved, but it may not be correct. Many issues are relevant for a sound benefit transfer method. For example, corrections must be made for population density and income differences. 


\section{$4 \quad$ Valuation based on the Environmental Footprint standard}

In LCA, the environmental impact is measured by an impact indicator with a specific unit to which all relevant interventions for the impact category are converted to and aggregated. For example, greenhouse gases such as methane are converted to carbon dioxide equivalents. As explained earlier, the indicator can be an endpoint indicator, which enables aggregation of several impact categories, and can also be midpoint indicators, which cannot be aggregated directly. Various methods exist for each impact category with different scopes and units to define the indicators. Ideally, a method defines indicators at both midpoint and endpoint level with potentially a non-linear but in practice mostly a linear relation between the two.

The choice of which impact assessment method to use for each impact category is often made based on the preference of the LCA expert. The European Commission has therefore developed a framework to assess the validity of existing methods and selected the currently best available methods for each impact category based on the criteria defined in the framework. All indicators of these selected methods are midpoint indicators, because the endpoint indicators are not considered robust enough. These selected methods are mandatory in the context of the Environmental Footprint (EF) initiative, but also outside this context the selection is applied worldwide as there is a general demand for alignment and the broad recognition for the work of the European Commission. These methods are also referred to as the EF methods.

The European Commission also developed normalisation factors, which are based on the environmental interventions which occurred in 2010 within the European Union. The results of the impact indicators can be divided by the results of this reference to obtain comparable units. The European Commission also developed weighting factors to enable aggregation of the indicators. The weighting factors are based on LCA expert and laymen judgement and are mandatory to select the most relevant impact categories. This approach was preferred over monetisation, because not all midpoint indicators can be covered and further refinements are needed.

This problem can be circumvented by combining the normalisation/weighting approach and monetisation. The weighted and aggregated results of the EF methods, which are expressed in Points (or in many cases MiliPoints), can be monetised indirectly. The LCA experts and laymen have indirectly expressed how they value each impact category, not in monetary units, but in relative importance. So, the value of a Point can be determined by minimising the difference between the resulting values per $\mathrm{kg} \mathrm{CO}$-eq, DALY, kg N-eq, etc. and available best guesses based on literature. The challenge in this approach is that not for all impact categories best guesses are available. For example, do we allow a large deviation from the best guess for climate change to enable a better match for eutrophication or respiratory inorganics? If we can solve this problem and find an acceptable value to monetise the weighted indicator, it is completely in line with the state-of-the-art LCA methodology recommended by the European Commission and followed by many companies and experts around the world. Therefore, an approach that uses standard LCA analyses and monetises the aggregated indicator has the advantage of being already broadly accepted and broadly discussed, and therefore seems a good starting point for developing more refined approaches taking into consideration insights that have already been developed.

Another issue that needs to be solved irrespective of this approach is how to determine best guesses for the impact categories for which it is possible.

- Some LCA midpoint indicators can be monetised directly, because of existing policies and/or methods. For example for climate change ( $\mathrm{kg} \mathrm{CO}_{2} \mathrm{eq}$ ). For others like eutrophication ( $\mathrm{kg} \mathrm{P}$ eq, $\mathrm{kg} \mathrm{N} \mathrm{eq}$ ) and land use ( $\mathrm{m}^{2}$.year) policies exist, but the size of the cost depends on the location and specific circumstances.

- For other impact categories, the endpoint indicators can be used, where the relations between the midpoints and endpoints is a constant factor that may depend on region and other characteristics. 
For example, respiratory inorganics (particulates) and photochemical ozone formation are converted from kg PM2.5 eq and kg NMVOC eq, respectively, to DALY; and there are methods for determining the value of a DALY. This also applies to human toxicity.

- Likewise, the midpoint indicators for ecotoxicity and acidification are converted to the endpoint unit for biodiversity (loss of species). The value of a species can be determined better than the value of for example a Comparative Toxic Units ecotoxicity (CTUe) or a mol H+eq.

- Fossil, mineral and metal resource uses are complex impact categories to valuate. There are no linear relationships between midpoint and endpoint indicators in these categories. In one LCA method, the endpoint indicator for these categories is a monetary unit (US\$ surplus cost). So, this indicator could be used in combination with the other monetised categories. Nevertheless, the surplus cost method may be debated and cannot be applied to the EF methods as there is no relation between the surplus cost and the selected indicators of the EF methods.

- Water scarcity is complex, because there is not only the surplus cost (the additional cost to be able to produce an extra cubic meter of freshwater, for example by desalinisation), but also the cost of damage on human health and ecosystems, which are geographically, temporally and culturally specific. Because of this complexity, it is not possible to define a midpoint indicator, which is linearly related to the endpoint indicators. This means that the valuation of water scarcity is preferably done on the endpoint indicators, i.e. human health, biodiversity and resource scarcity. This cannot be applied to the EF methods as there is no relation between the surplus cost and the selected indicators of the EF methods.

Table 1 gives a very preliminary overview of valuation methods and ranges of monetisation values for each impact category. 
Table 1

\begin{tabular}{|c|c|c|}
\hline Impact category & Valuation method & Ranges \\
\hline \multirow[t]{3}{*}{ Climate change } & Social cost of carbon & $\begin{array}{l}21-900 \text { US } \$(2010) / \text { tonne } \mathrm{CO}_{2}(\text { Ackerman } \& \text { Stanton, } 2012) \\
\text { (equal to about } 30-1,200 €(2018) / \text { tonne } \mathrm{CO}_{2} ; 1.5 \% \text { inflation and } \\
0.85 € / \text { US } \$ \text { ) }\end{array}$ \\
\hline & Abatement cost & $\begin{array}{l}150-500 \text { US\$(2010)/tonne } \mathrm{CO}_{2} \text { (Ackerman \& Stanton, 2012) } \\
14-57 €(2015) / \text { tonne } \mathrm{CO}_{2} \text { (de Bruyn et al., 2017) }\end{array}$ \\
\hline & Best guesses & $\begin{array}{l}220 \text { US\$(2010)/tonne } \mathrm{CO}_{2} \text { (Fitzpatrick et al., } 2015 \text { and Moore \& Diaz, } \\
2015) \text { (equal to roughly } 300 €(2018) / \text { tonne) } \\
128 \text { US\$/tonne } \mathrm{CO}_{2} \text { (USIAWG, 2013) } \\
57 €(2015) / \text { tonne } \mathrm{CO}_{2} \text { (de Bruyn et al., 2017) } \\
83 €(2008) / \text { tonne } \mathrm{CO}_{2} \text { (Weidema, 2009) (equal to about } 96 \\
€(2018) / \text { tonne) } \\
\text { Average: } 150 €(2018) / \text { tonne } \mathrm{CO}_{2}\end{array}$ \\
\hline $\begin{array}{l}\text { Human health } \\
\text { (particulates, } \\
\text { toxicity, } \\
\text { photochemical } \\
\text { ozone formation) }\end{array}$ & Budget constraint & $\begin{array}{l}\text { 50-100 k€(2015)/DALY (de Bruyn et al., 2017). } \\
\text { 18-151 k€(2003)/DALY; (Markandya et al.) } \\
\text { 25-100 k€(2005)/DALY; Desaigues et al. (2006) } \\
\text { Combined: about 23-189 k€(2018)/DALY } \\
\text { Note: depends on the perspective/income level }\end{array}$ \\
\hline ozone formation) & Best guess & 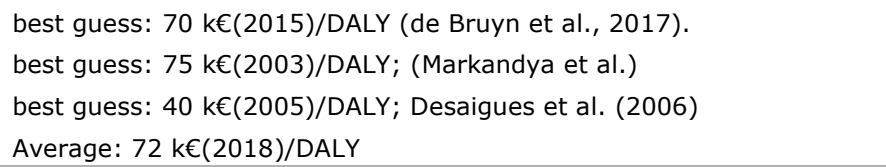 \\
\hline \multirow[t]{4}{*}{ Eutrophication } & Abatement cost: & $\begin{array}{l}\text { in the Netherlands } 3.11 €(2015) / \mathrm{kg} \mathrm{N} \text { and range } 0.5-3.7 \text { with best } \\
\text { guess } 1.9 €(2015) / \mathrm{kg} \mathrm{P} \text { (de Bruyn et al., 2017) } \\
\text { Note: very specific to local policies }\end{array}$ \\
\hline & Social damage cost & Note: depends on local situation \\
\hline & Budget constraint & $0.44 €(2003) / \mathrm{kg} \mathrm{N}$ or $6.28 €(2003) / \mathrm{kg} P$ (based on Weidema, 2009) \\
\hline & Ecological damage & see biodiversity \\
\hline $\begin{array}{l}\text { Land use } \\
\text { (ecosystem } \\
\text { services) }\end{array}$ & $\begin{array}{l}\text { Combination of Direct } \\
\text { market price/avoided } \\
\text { cost/replacement } \\
\text { cost/Contingent Valuation }\end{array}$ & $\begin{array}{l}0.03-0.52 \$ / \mathrm{m}^{2} \text {.year (de Groot et al., 2012) } \\
\text { Note: EF method for land use gives a country and land use specific } \\
\text { indicator for services of soils - erosion control, filtration, groundwater } \\
\text { regeneration and biotic production. There are however no ways to } \\
\text { directly monetise this indicator. }\end{array}$ \\
\hline Land use change & $\begin{array}{l}\text { Land-use values considering } \\
\text { ecosystem services provided } \\
\text { by different types of } \\
\text { ecosystems specific to each } \\
\text { country }\end{array}$ & $\begin{array}{l}0.12 \text { US } \$ / \mathrm{m}^{2} \text { (Baltussen et al., 2017, referring to Trucost, 2016, who } \\
\text { refer to de Groot et al., 2012) }\end{array}$ \\
\hline
\end{tabular}


In order to compare the standard LCA aggregation method combined with a value per point with outcomes of valuation studies, Table 2 shows prices based on a price per LCA points and the number of LCA points for the impact category, and best guesses and ranges of prices found in the literature. The price per LCA point is based on minimisation of the difference between best guesses and prices based on LCA points. Most values based on LCA points are well within the ranges found in the literature (climate change, photochemical ozone formation, respiratory inorganics, non-cancer human health, and water scarcity). The values for other categories are higher than the ranges: human health cancer effects, eutrophication freshwater and eutrophication marine. The question is whether we find these outliers acceptable. The overestimation of the value for human health cancer effects is relatively small. The overestimation of the value for eutrophication marine is more considerable, though the question may also be whether the estimated range is underestimating the value. The value for eutrophication freshwater is much higher than the best guess. However, when we consider the contribution of these impact categories to the total score, the deviations from the best guesses may have only small effects. For example, the contribution of eutrophication freshwater in an LCA study to the impact of milk is $0.7 \%$ when based on LCA points and would be $0.0 \%$ if the best guess estimate would be used.

Table 2 Comparison of environmental prices based on a price for LCA points and estimates in the literature

\begin{tabular}{|c|c|c|c|}
\hline Impact category & Unit & Best guess (range) & LCA point pricing \\
\hline Climate change & $€ / \mathrm{kg} \mathrm{CO} 2$ eq & $0.15(0.03-1.2)$ & 0.14 \\
\hline Ozone depletion & $\mathrm{k} € / \mathrm{kg}$ CFC11 & No data & 14 \\
\hline Photochemical ozone formation & $€ / \mathrm{kg}$ NMVOC & $6.21(0.89-9.2)$ & 6.1 \\
\hline Respiratory inorganics & $\mathrm{k} € / D A L Y$ & $72(23-189)$ & 36 \\
\hline Cancer human health effects & $\mathrm{k} € / D A L Y$ & $72(23-189)$ & 251 \\
\hline Acidification & $€ / \mathrm{mol} \mathrm{H}+\mathrm{eq}$ & No data & 5.9 \\
\hline Eutrophication freshwater & $€ / \mathrm{kg} \mathrm{P}$ eq & $2(-)$ & 57 \\
\hline Eutrophication marine & $€ / \mathrm{kg} \mathrm{N}$ eq & $3.1(0.5-3.7)$ & 5.5 \\
\hline Water scarcity & $€ / \mathrm{m}^{3}$ & $0.045(0.006-1.175)$ & 0.039 \\
\hline Resource use, energy carriers & $€ / M J$ & No data & 0.0066 \\
\hline Resource use, mineral and metals & $€ / \mathrm{kg} \mathrm{Sb}$ eq & No data & 0.68 \\
\hline Single score & $€ / L C A$ millipoint & - & 5.21 \\
\hline
\end{tabular}

The resulting values of the single score is 5.21 $€$ /LCA Point. When for example the LCA impact of a $\mathrm{kg}$ of cow milk is calculated based on ecoinvent data the result is 0.172 LCA millipoints and this would imply that the cost of the environmental impact is about $0.90 € /$ litre. 


\section{Valuation based on the ReCiPe 2016 method}

If we would not follow the EF methods, another approach could be based on the ReCiPe 2016 midpoint and endpoint methods. Some impact categories can then be monetised using the best guesses at midpoint as described in the previous section and others can be monetised at endpoint level. For human health, the estimate is $72 \mathrm{k} € / D A L Y$, and for ecosystems the estimate is $11.510^{6}$ $€ /$ species.year based on a value for land use of $0.10 € / \mathrm{m} 2$.year (based on Baltussen et al., 2017). So, in the cases where a value based on midpoint is available, it replaces the value based on endpoint (Table 3). The environmental impact of 1 litre of milk using this approach would be about $€ 0.65$.

The problem with this approach is that it is very sensitive to the assumptions for estimating the value for land use and other estimates at midpoint level. It is difficult to justify the choices for best estimates, which makes the outcome arbitrary. Moreover, each estimate can be disputed individually. This means that the contribution of each impact category can vary depending on the choices made for each impact category. Another disadvantage is that no country-specific characterisation factors are available for land use as is the case in the EF methods.

Table 3 Values based on the endpoint and midpoint impact categories of the ReCiPe 2016 method (where a value based on midpoint is available, it replaces the value based on endpoint)

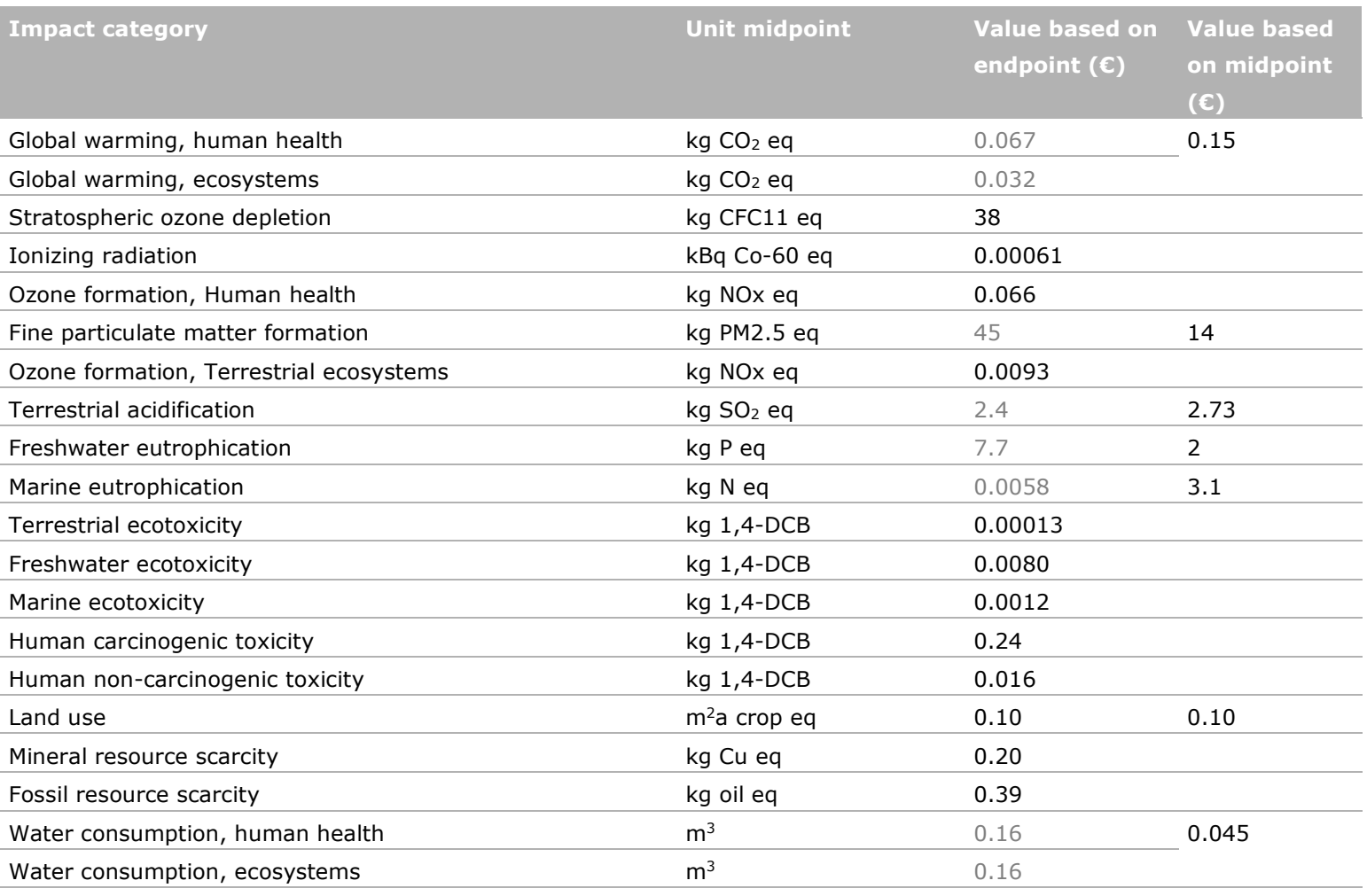




\section{Other approaches}

Two references that transparently report monetisation methods based on life cycle impact analysis methods are reviewed: the Shadow Prices method connected to ReCiPe 2008 (De Bruyn et al.) and the monetisation method integrated in the Stepwise method (Weidema, 2009).

\subsection{CE Delft shadow price calculation (De Bruyn et al., 2017)}

The method is connected to the life cycle impact analysis method ReCiPe 2008 and the impact pathway approach NEEDS (2008). ReCiPe 2008 has in between been replaced by ReCiPe 2016. The units of the indicators in the new version of ReCiPe are largely the same, but the values of the monetisation method cannot be applied directly to the new method because several values are based on the mid-to-endpoint factors of the old version. However, one may be able to adapt the prices to the new version.

NEEDS is focused on energy pathways and has a four-step approach. The first step is estimation of the source emissions. The second step is the spread of the source emissions over the region resulting in changes in concentration. The third step is the calculation of the effect of the changes in concentration on endpoint indicators using concentration response functions and population density. For morbidity the VOLY is used as an endpoint indicator. The last step is the monetary valuation of the endpoint indicators. Changes in agricultural productivity can be valued at market prices, while for effects on materials and buildings repair cost can be used as an estimate. For health and ecosystems an estimate is made based on stated preference studies (see De Bruyn et al., 2017, p. 170).

Briefly summarised:

- Climate change: the cost in $€ / \mathrm{kg} \mathrm{CO} 2$ eq is based on abatement cost as estimated by CPB and PBL (2016), which is endorsed by Dutch government. They did not choose for applying damage cost because they argue that this is still extremely uncertain.

- Human health damage by impacts other than climate change is valued by the budget constraint method, based on literature average.

- Biodiversity damage is based on Kuik et al. (2008), who have done a study on the WTP for biodiversity, combined with Ott et al. (2006) who estimate restoration cost of losses of biodiversity for Germany (CE-Delft, 2017, p. 189).

- Ecosystems services: mentioned, but possibly not included.

- Eutrophication damage on water services: abatement cost based on Dutch policy and institutions.

\subsection{Stepwise (Weidema)}

The life cycle impact analysis method by Weidema (2009) has different equivalence indicators than ReCiPe, but the monetisation factors are based on the human health and ecosystems quality endpoint indicators, which are the same or compatible. A third impact is added for impacts on resource productivity, which is applied to mineral resource extraction and human health impact categories.

Summarised:

- Human health damage is valued by the budget constraint method, based on literature average. Budget constraint method is a method that takes income that you can spend on saving a life into account. It is assumed that the yearly income can be used for that.

- Biodiversity is based on some assumptions and the current environmental protection expenditures in developed countries to convert the human health damage to biodiversity damage. 
- 'Resource productivity' is measured as the future economic output in monetary units (but not clear how the values were determined); fossil resource depletion is not included.

- Ecosystem services are not included.

- The method does not take specific land use types and spatially specific interventions into account. 


\section{$7 \quad$ Uncertainty analysis}

The outcomes of environmental cost estimates are very uncertain. First, the emissions and other effects of specific processes are uncertain. Emissions or changes in land characteristics are normally not directly measured, so some standard values for the type of process chosen must be used. This is normally done in a rough manner and this may generate biases. First, the effect may be sector specific. For example, the biodiversity effect of land use is calculated based on the average effect of changing land use to annual crops, the effect of potatoes as an annual crop may be different from maize as an annual crop, which is not considered. Second, the effect may be location specific. In regions with a high population density or very sensitive nature the consequence of the same level of pollution may be more severe. Third, the effect may be technology or process specific. For example, if less polluting cars are used for transport, the effect may be smaller.

In aggregating indicators for specific processes the difference in consequences may be even larger. For example, if pollution in densely populated areas with high pollution levels are aggregated with pollution in areas with low population density and low pollution levels, the comparison may become meaningless. This implies that some weighting has to take place to aggregate indicators, but in weighting some arbitrary decisions have to be made.

When putting monetary prices to the different environmental effects also a lot of uncertainty arises. For example, an abatement cost approach gives different value than a willingness to pay approach (see Figure 4). A willingness to pay approach has different results depending on the method used and the question if a willingness to accept or a willingness to pay method is used. An abatement cost approach is also very uncertain because if it is calculated based on existing technologies and scale, while increases in scale or learning by doing may reduce cost, while also new technologies may emerge.

In summary, there are many sources of uncertainty and therefore, the absolute figures resulting from calculating the external cost of a product are meaningless without also showing the uncertainty range. A standard way to analyse uncertainties is Monte Carlo analysis. In Monte Carlo analysis many simulations are run based on different selections out of uncertainty distributions. One may for example take the mean, minimum and maximum values per impact category for these uncertainties, or make assumptions on the probability distributions. As far as differences in weighting are relevant, for example about prices for environmental costs, one may use for the simulation of a number of alternative options the same price assumptions per run, and calculate the difference in all these options. By varying this one may see to what extent one option is the best under all plausible relative price assumptions.

An important issue for externalities with long-term consequences or changes in stocks, like climate change, is the time frame to look at. For example, ReCiPe (Huijbregts et al., 2017) distinguishes three time perspectives in what they call the Cultural Theory framework. The default is the Hierarchy approach (typified by a 100-year time horizon) and the alternatives are the Individualist (20-year time horizon) and the Egalitarian perspective (500-year time horizon). Instead of a timeframe, a discount rate can be used to account for future cost of the environmental damage. For the surplus cost of fossil and mineral resource depletion in ReCiPe, different discount rates are applied depending on the perspective in line with the time horizons for the other impact categories.

The standard software used for LCA, SimaPro LCA software, contains uncertainty indicators per input and output for each process and such indicators can be added to foreground data (i.e. data gathered specifically for the case that is investigated) as well. The software has a Monte Carlo analysis function, also for comparing 2 cases. However, there is no function to assess the uncertainty of impact analysis methods (including valuation), except for the alternative sets of characterisations factors of ReCiPe like the time horizon. This could be done with other software, such as Excel, R or Matlab, but this can then only indirectly be combined with the inventory data uncertainty by using the uncertainty distribution of the Monte Carlo results with SimaPro. 


\section{Conclusion}

The EU methodology for LCA seems to be a broadly supported approach to environmental impact assessment that has standardised software available for implementation that includes opportunities for uncertainty analysis. When a final indicator is calculated in LCA this may be used directly to determine values for different environmental categories based on the LCA analysis. Therefore, we suggest to start our approach with a careful investigation of the LCA methodology and add a monetary valuation to this methodology. A first attempt to such a check is done in this report in Table 2 , but this must be developed much further. It seems logical to compare this approach with other approaches like ReciPe 2016, toolkits for cost-benefit analysis (including the CE Delft approach for environmental prices in the Netherlands), the methodology developed by TruePrice, and the approach of The Sustainability Consortium.

De Groot Ruiz et al. (2018) give an overview of the methods per sustainability issue and per stage (identification, qualification, quantification and monetisation). This overview shows that monetisation is one of steps to make the different sustainability issues more comparable. Several consortia are working on monetisation:

- TEEB (The Economics of ecosystems and biodiversity) http://www.teebweb.org/

- http://teebweb.org/agrifood/home/teebagrifood/

- Natural Capital Coalition: https://naturalcapitalcoalition.org/

- http://naturalcapitalcoalition.org/protocol/sector-guides/food-and-beverage/

- https://www. naturalcapitaltoolkit.org/

- Trucost

- https://www.greenbiz.com/report/state-green-business-report-2018

https://www.trucost.com/

- http://www.eosta.com/nl/nieuws/true-cost-accounting-pilot-berekent-verborgen-kostenvoedselproductie

- True price: http://trueprice.org/nl/

- Food System Impact Valuation http://www.eci.ox.ac.uk/news/2017/1205.html

- The Sustainability Consortium 


\section{References and websites}

Baltussen, W. \& et al. (2017). Maatschappelijke effecten van voedsel: een verkenning van een nieuwe methodiek, Wageningen Economic Research.

Bruyn, S. D., Ahdour, S., Bijleveld, M., Graaff, L. D., Schep, E., Schroten, A. \& Vergeer, R. (2017) Handboek Milieuprijzen 2017: Methodische onderbouwing van kengetallen gebruikt voor waardering van emissies en milieu-impacts, Delft, CE Delft.

De Groot Ruiz, Adrian, Willy Baltussen, Renier de Adelhart Toorop, Floor van den Elzen, Bas Janssen, Roland van Keeken, Katja Logatcheva, Evelijn Martinius, Tommie Ponsioen (2018). Op weg naar de echte prijs, echte waarde en echte winst van voedsel; Een routekaart om te sturen op de maatschappelijke effecten van voedsel. Wageningen Economic Research, Rapport 20.

Holland, M. (2014). Cost-benefit Analysis of Final Policy Scenarios for the EU Clean Air Package Version 2 Corresponding to IIASA TSAP Report 11, Version 1, sl: EMRC.

Johnston, Kevin J., Boyle, Wiktor (Vic) Adamowicz, Jeff Bennett, Roy Brouwer, Trudy Ann Cameron, W. Michael Hanemann, Nick Hanley, Mandy Ryan, Riccardo Scarpa, Roger Tourangeau, Christian A. Vossler (2017). Contemporary Guidance for Stated Preference Studies. JAERE, 4(2), p. 319-405.

Kuik, O. Brander, L., Nikitina, N., Navrud, S., Magnussen, K., Fall, E.H. (2007). A Database of Studies on Energy-related External Costs due to Land Use Changes, Acidification and Eutrophication, Visual Intrusion and Climate Change. CASES Project, EU DG Research, Brussels.

Kuik, O. et al. (2007). Cost Assessment of Sustainable Energy Systems (CASES): D. 3.2 Report on the monetary valuation of energy related impacts on land use changes, acidification, eutrophication visual intrusion and climate change, Amsterdam: Institute for Environmental Studies (IVM).

Kuik, O., Brander, L. \& Tol, R. (2009). Marginal abatement costs of greenhouse gas emissions: A meta-analysis. Energy Policy, 37(4), pp. 1395-1403.

Markandya, A., Hunt, A., Arigano, R., Desaigues, B., Bounmy, K., Ami, D., Masson, S., Rabl, A., Santoni, L., Salomon, M.-A., Alberini, A., Scarpa, R., Krupnick, A. (2004). Monetary valuation of increased mortality from air pollution. Chapter III In: Friedrich, R. (Ed.), New Elements for the Assessment of External Costs from Energy Technologies (NewExt). Final Report to the EuropeanCommission,DGResearch,TechnologicalDevelopment and Demonstration (RTD). http://www.ier.uni-stuttgart.de/forschung/projektwebsites/newext/newext_final.pdf.

National Academies of Sciences, Engineering, and Medicine (2017). Valuing Climate Damages: Updating Estimation of the Social Cost of Carbon Dioxide. Washington, DC: The National Academies Press. doi: https://doi.org/10.17226/24651.

Pizzol, M., Weidema, B., Brandao, M. \& Osset, P. (2015). Monetary valuation in Life Cycle Assessment: a review. Journal of Cleaner Production, 86, 170-179.

Pretty, J. N., Mason, C. F., Nedwell, D. B., Hine, R. E., Leaf, S., \& Dils, R. (2003). Environmental costs of freshwater eutrophication in England and Wales.

Ready, R. et al. (2004), "Benefit Transfer in Europe: How Reliable Are Transfers between Countries?" Environmental and Resource Economics, 29, 67-82.

Rivm (2016). ReCiPe 2016, Available at:

https://www.rivm.nl/Documenten_en_publicaties/Wetenschappelijk/Rapporten/2016/december/Re CiPe_2016_A_harmonized_life_cycle_impact_assessment_method_at_midpoint_and_endpoint_lev el_Report_I_Characterization/Download/ReCiPe_2016_A_harmonized_life_cycle_impact_assessme nt_method_at_midpoint_and_endpoint_level_Report_I_Characterization.pdf.

Tegtmeier, E. M., \& Duffy, M. D. (2004). External costs of agricultural production in the United States. International Journal of agricultural sustainability, 2(1), 1-20.

TruCOST (2016). Top down methodology: TEEB Animal Husbandry, Available at: http://www.teebweb.org/wp-content/uploads/2017/08/Top-down-methodology_TEEB-AnimalHusbandry_v2.pdf.

Weidema, B. P. (2009). Using the budget constraint to monetarise impact assessment results. Ecological economics, 68(6), 1591-1598. 
Wageningen Economic Research P.O. Box 29703

2502 LS The Hague

The Netherlands

$\mathrm{T}+31(0) 703358330$

E communications.ssg@wur.nl

www.wur.eu/economic-research

Wageningen Economic Research REPORT

2020-010
The mission of Wageningen University \& Research is "To explore the potential of nature to improve the quality of life". Under the banner Wageningen University \& Research, Wageningen University and the specialised research institutes of the Wageningen Research Foundation have joined forces in contributing to finding solutions to important questions in the domain of healthy food and living environment. With its roughly 30 branches, 5,000 employees and 12,000 students, Wageningen University \& Research is one of the leading organisations in its domain. The unique Wageningen approach lies in its integrated approach to issues and the collaboration between different disciplines. 



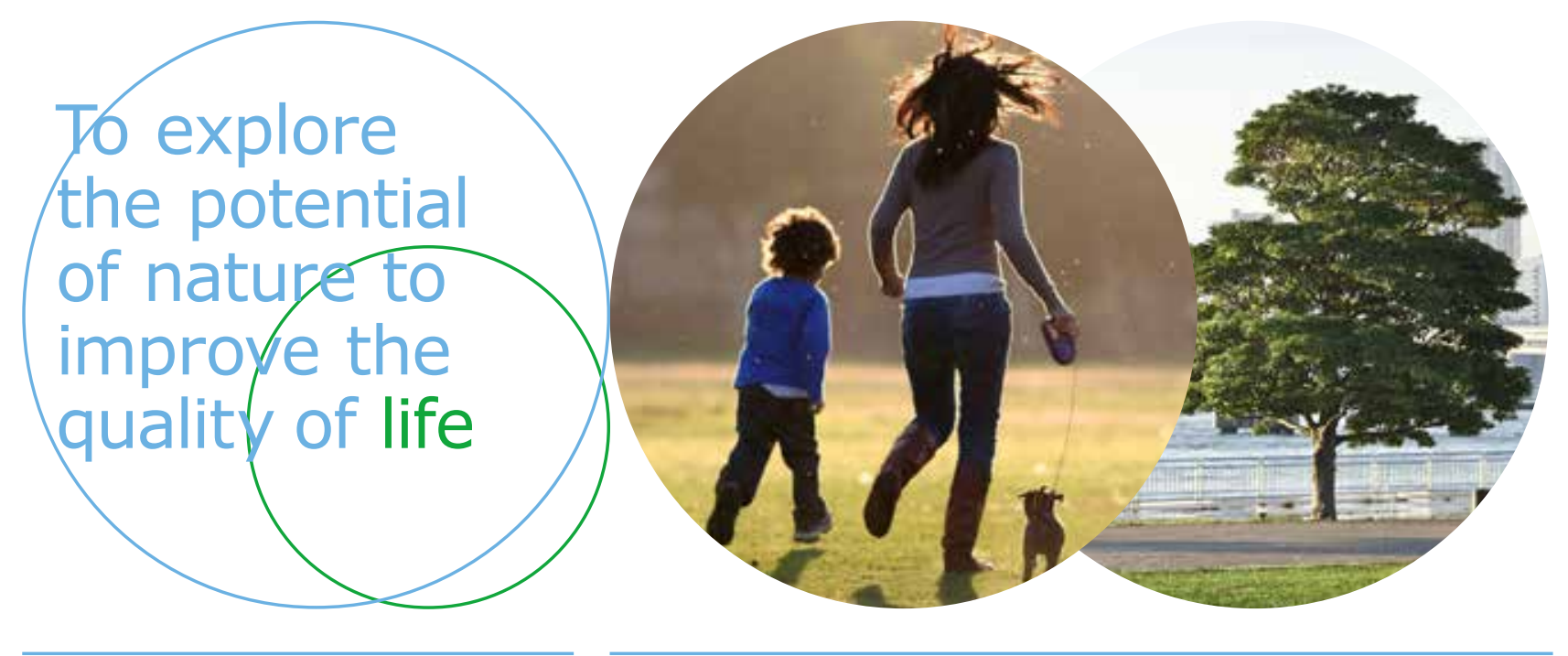

Wageningen Economic Research P.O. Box 29703

2502 LS Den Haag

The Netherlands

$\mathrm{T}+31(0) 703358330$

E communications.ssg@wur.nl

www.wur.eu/economic-research

Report 2020-043

ISBN 978-94-6395-418-1
The mission of Wageningen University \& Research is "To explore the potential of nature to improve the quality of life". Under the banner Wageningen University \& Research, Wageningen University and the specialised research institutes of the Wageningen Research Foundation have joined forces in contributing to finding solutions to important questions in the domain of healthy food and living environment. With its roughly 30 branches, 5,000 employees and 12,000 students, Wageningen University \& Research is one of the leading organisations in its domain. The unique Wageningen approach lies in its integrated approach to issues and the collaboration between different disciplines. 